\title{
Correction to: Substrate-Assisted Electrosynthesis of Patterned Lamellar Type Indium Selenide (InSe) Layer for Photovoltaic Application
}

\author{
A. B. Bhalerao, S. B. Jambure, R. N. Bulakhe, S. S. Kahandal, \\ S. D. Jagtap, A. W. M. H. Ansari, Insik In, and C. D. Lokhande
}

Correction to:

Chapter "Substrate-Assisted Electrosynthesis of Patterned Lamellar Type Indium Selenide (InSe) Layer for Photovoltaic Application" in: M. Bose and A. Modi (eds.), Proceedings of the 7th International Conference on Advances in Energy Research, Springer Proceedings in Energy, https://doi.org/10.1007/978-981-15-5955-6_79

In the original version of this chapter, the author "A. G. Banpurkar" name was included erroneously as a co-author. This has now been rectified and the author name has been removed. 